\title{
A scanner for in situ X-ray radiography of large paintings: the case of "Paolo and Francesca" by G. Previati
}

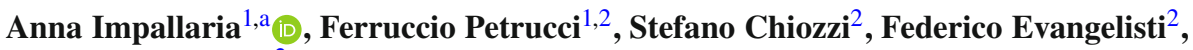 \\ Stefano Squerzanti ${ }^{2}$ \\ ${ }_{1}^{1}$ Department of Physics and Earth Science, University of Ferrara, Ferrara, Italy \\ 2 INFN-Ferrara, Ferrara, Italy
}

Received: 28 August 2020 / Accepted: 8 January 2021

(C) The Author(s) 2021

\begin{abstract}
A scanner for digital radiography of large paintings has been designed and developed, aimed to in situ performances. We report here the application to "Paolo and Francesca" $\left(260 \times 230 \mathrm{~cm}^{2}\right)$, masterpiece by the Italian divisionist painter Gaetano Previati (1909). The scanner has given the whole radiography in $1137 \mathrm{X}$-ray shots, which were corrected for X-ray inhomogeneities and finally processed, minimizing the visual impact of the frame structure. The original version of the painting has been brought to the light, and it appears to be a further step in the evolution of the theme frequently experienced by the artist.
\end{abstract}

\section{Introduction}

Nowadays, scientific analyses on cultural objects are routinely performed directly in situ, through spot and imaging techniques [1-3], avoiding risks due to the movement of the works of art $[4,5]$. Several research groups are focusing on portable instruments and on their development in order to get performances closer to the laboratory standard [6-15].

Imaging diagnostics in situ is still challenging on large objects. In fact, their analyses often require an accurate and organized project. Moreover, their movement in the same museum or gallery in which they are conserved could not be so handily and could require specialized staff. Many research groups performed analyses on various type of large objects: the tomography of the Celestial Globe of Vincenzo Coronelli, which is $1.06 \mathrm{~m}$ of diameter [5], or the study of painting materials used by Vittore Carpaccio in "The meeting of the pilgrims with the Pope" $(279 \times 305 \mathrm{~cm})[16]$ and by Jacopo Tintoretto in "Wedding feast in Cana" $(435 \times 545 \mathrm{~cm})$ [17].

Other examples, for in situ application, are about the CT scanner [18], which gives more information about real 3D objects, but for paintings $\mathrm{X}$-ray radiography is the technique most required.

The radiography of large masterpieces is often required for conservation and restoration purposes. The most important advantages of the digital radiography are the huge range of grey

\footnotetext{
a e-mail: impallaria@fe.infn.it (corresponding author)
} 
levels, which means more information, and the digital correction of images, which allows to correct the anomalies of the X-ray tube effects [19].

A scanner suited for the digital radiography of large paintings has been developed at "La Venaria Reale", the restoration centre in Turin (Italy) by the research group of INFN (National Institute of Nuclear Physics) and University of Turin [20,21]. But, in this case, the scanner is fixed because it is devoted to the use by restorers at the centre. The maximum dimensions of the painting to be radiographed are $3 \times 4 \mathrm{~m}^{2}$, and it has to be moved to the X-ray irradiation laboratory.

Our efforts in these last years were devoted to the development of a X-ray radiographic scanner transportable to museums, galleries and restoration laboratories and working on both small and large size paintings [19,22,23].

The scanner for digital radiography developed by INFN and University of Ferrara was thought as the most flexible as it was possible. The scanner is composed of two separate units - and this makes transport easier-one devoted to the movement of the X-ray tube and one to the movement of the digital detector $[19,24]$.

The units are disjoint, but they work synchronized to ensure the same alignment for all the radiographic images acquired.

When each unit is clamped to a scaffold, the size of the painting is not a limit for its whole radiography, unlike the common X-ray baggage scanner, based on a tunnel-like system of limited width.

In this paper we present its use tailored for a very large size painting: "Paolo and Francesca" depicted by Gaetano Previati in 1909, a canvas of $260 \times 230 \mathrm{~cm}^{2}$. For analysing this masterpiece, we kept the X-ray tube fixed and used only the detector unit to perform the scanning. Due to the dimensions of the unit which allows to scan an area of ca. $1 \mathrm{~m}^{2}$ and to the uniformity of the X-ray beam, we divided the scan of the whole painting in 12 squares and lifted the system in order to scan the central squares of the painting. The application of our instrument to the case study of "Paolo and Francesca" gave the opportunity to test the flexibility of the scanner in challenging conditions and to evaluate the best procedure for the radiography of large paintings.

\subsection{Historical notes on the painting "Paolo and Francesca" by Gaetano Previati}

Gaetano Previati (Ferrara 1851-Lavagna 1920) was the most important divisionist Italian artist. In 1909 he published its treatise "The scientific principles of Divisionism" and in the same year he depicted the big painting "Paolo and Francesca", an oil on canvas, $260 \times 230 \mathrm{~cm}^{2}$, conserved at the Modern and Contemporary Art Gallery of Ferrara (Fig. 1). The painting shows the two lovers as they are described in the Canto 5 of Inferno in the "Divine Comedy" by Dante Alighieri: they are embracing one to the other and surrounded by other damns in the whirlwind.

The theme is not new for the author who, in 1887, following the realistic current, painted Paolo and Francesca in the moment of their death. For the painting of the 1909, Previati depicted a lot of sketches focusing on the composition of the bodies and one was presented at the IV Biennale of Venice in 1901, demonstrating the long thinking and creative process of the artist about this issue [25].

The painting is conserved since 1911 at the Modern and Contemporary Art Gallery in Ferrara.

In 2018, the painting was exposed at the "States of Mind. Poetics of the self from Previati to Boccioni" exhibition at Palazzo dei Diamanti in Ferrara. Before the exhibition, the frame of the painting was changed because the previous one was at the maximum of its extension. In this occasion, a diagnostic campaign was performed to access the conservation state of 
Fig. 1 Gaetano Previati, Paolo and Francesca, 1909, oil on canvas, $260 \times 230 \mathrm{~cm}$, Modern and Contemporary Art Gallery, Ferrara. The photograph refers to the conservation state in May 2017

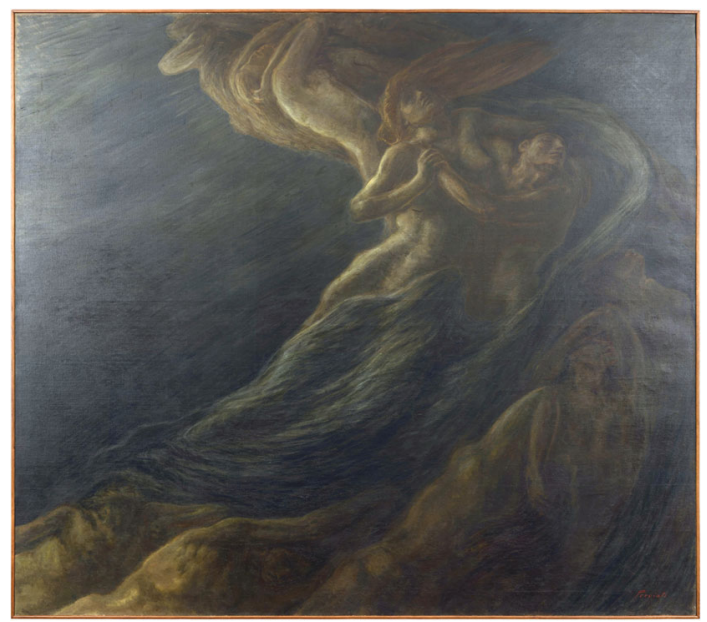

the work of art and to study the artistic technique. The CNR (National Research Council) and the INFN-CHNet (Cultural Heritage Network) group of Ferrara, in collaboration with the University, were charged with full documentation on imaging techniques of the whole painting. All the techniques were applied at the Contemporary Art Pavilion in Ferrara, with the support of the Gallery staff.

\section{Materials and methods}

\subsection{X-ray radiography procedure}

The digital radiography has been performed moving the detector in order to scan an area of the canvas, while the X-ray tube was stationary, illuminating the same area (Fig. 2), $2 \mathrm{~m}$ apart. The distance between the X-ray tube and the detector was evaluated in order to obtain the maximum homogeneity in the beam lightening the scanning area. The difference in beam intensities from the centre to the borders of this area is less than $20 \%$.

The X-ray tube employed is the YXLON EVO 160D, with Tungsten anode, $160 \mathrm{kVp}$ and $7 \mathrm{~mA}_{\max }$. The parameters set for the painting were $30 \mathrm{kV}$ and $60 \mathrm{mAs}$. The digital detector is a Teledyne DALSA flat panel, composed by a CMOS matrix of photodiodes coupled with a scintillator screen of $\mathrm{Gd}_{2} \mathrm{O}_{2} \mathrm{~S}, 1024 \times 1000$ pixel, $96 \mu \mathrm{m}$ side. The depth of digitization at 12 bit/pixel allows to work with 4096 grey levels.

To collect all the radiographic images needed to reconstruct the whole painting, the acquisition has been divided in 12 squares (Fig. 3), overlapping of a row or a column of images with the closest squares. In each square, the acquired images are overlapping each other of $20 \%$ for the automatic stitching of all the images with no intervention of the operator. The stitching software is PTGuil0 by New House Internet Services BV (the Netherlands), a commercial software conceived for the stitching of photographs. The radiography of the central parts of the canvas was made lifting both the X-ray source and the detector stage, while for the upper parts, the painting was turned upside down. The X-ray tube was placed on an elevator, while the detector stage was put on a wooden trunk maintaining the same distance between them. The total number of radiographic shots on the painting was 1137 , 
Fig. 2 The radiographic scanner during the acquisition of X-ray images of the central parts of the painting. In foreground the detector unit and the painting, in background the X-ray tube
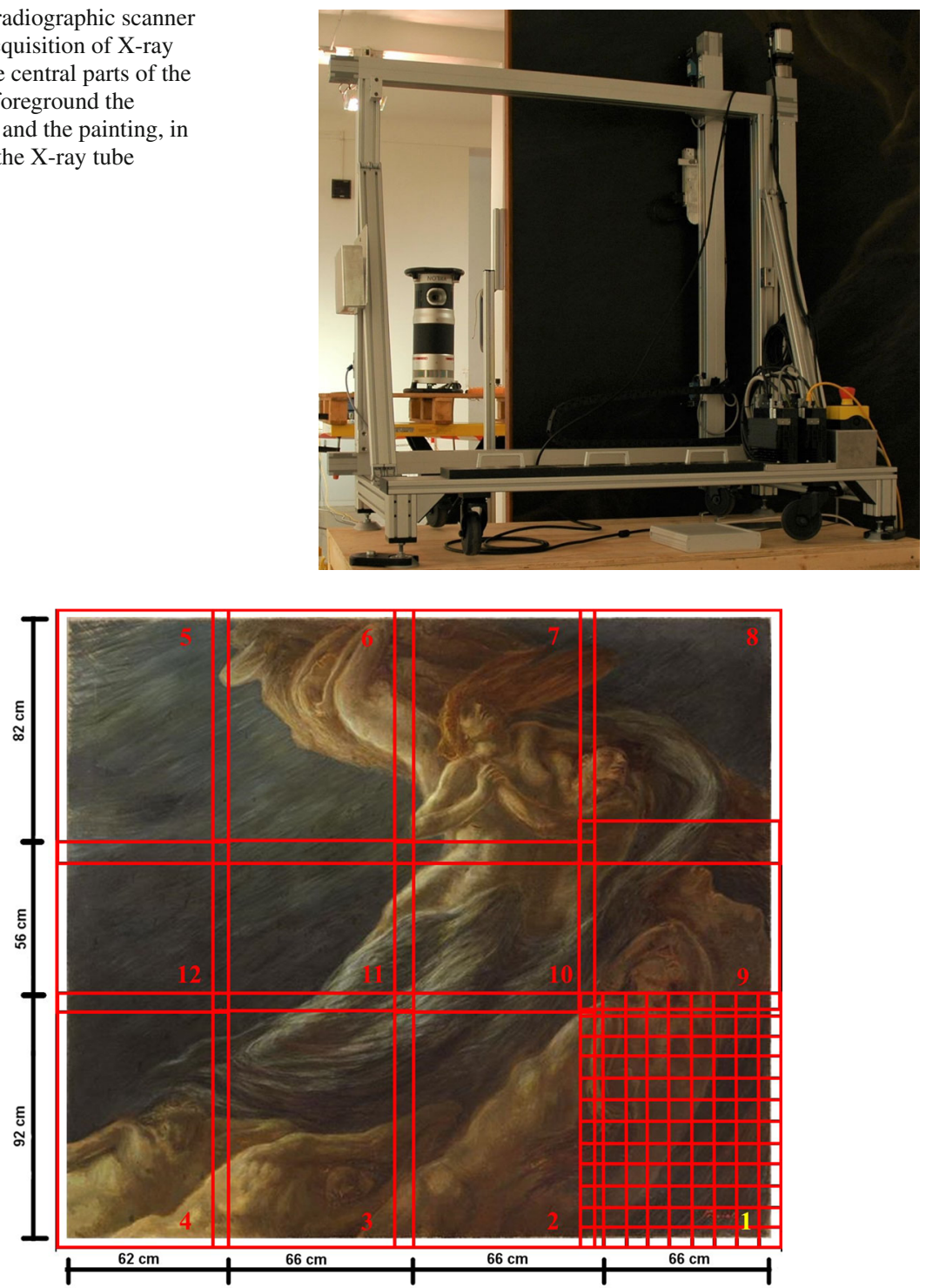

Fig. 3 Scheme of the 12 squares for the acquisition of the whole painting

acquired in 6 days (Table 1). A new set of correction images was acquired each day and at any movement of the scanner, to be sure that small changes in the relative position didn't influence the digital correction.

\subsection{Digital correction of X-ray images}

The first digital processing applied to all the radiographic images was the dark-white correction. For each set of radiographies, we have the dark-field image, acquired without the emission of X-ray beam and corrects the dark current spread on the $10^{6}$ photosites of the 
Table 1 For each square the dimensions and the number of X-ray shots acquired are reported

\begin{tabular}{llcc}
\hline Square & Dimensions $(\mathrm{cm})$ & X-ray images & White fields \\
\hline 1 & $74 \times 94$ & 108 & 108 \\
2 & $74 \times 94$ & 108 & 108 \\
3 & $74 \times 94$ & 108 & \\
4 & $64 \times 94$ & 96 & 96 \\
5 & $64 \times 94$ & 96 & \\
6 & $74 \times 94$ & 108 & 108 \\
7 & $74 \times 94$ & 108 & \\
8 & $74 \times 94$ & 108 & \\
9 & $74 \times 94$ & 81 & 81 \\
10 & $74 \times 63$ & 72 & 72 \\
11 & $74 \times 63$ & 72 & 8 \\
12 & $67.5 \times 63$ & 72 & 581 \\
X-ray shots & & 1137 & \\
\hline
\end{tabular}

detector. The white-field images, on the contrary, are images acquired with the emission of the X-rays in the same conditions of the radiographic shots, but without the sample. These last correct the lack of uniformity in the intensity of the beam from the X-ray source and in the acquisition of the detector. In Fig. 4, it is shown an example of the stitching of some images without the dark-white correction (Fig. 4a) compared to the corrected ones (Fig. 4b). The lack of uniformity of both the X-ray beam and the detector response allows to recognize the shape of the single uncorrected images. The dark and white corrections eliminate these elements and allow to show the results due only to the sample.

The final image converted to $8 \mathrm{bit} / \mathrm{pixel}$ in TIFF format (Fig. 5) is $27648 \times 24448$ pixels, $643 \mathrm{MB}$ in size.

\subsection{Digital processing of the whole radiography}

In the complete radiography (Fig. 5) the presence of wood elements in the painting could affect the readability of the image. Among the advantages of the digital images is the possibility of processing to eliminate the contributions of those elements [26,27]. The huge range of grey levels is enough to obtain well-contrasted and informative images both for the canvas areas and for the wooden elements, just choosing the grey levels in the histograms of the images.

A typical radiography of canvas and wooden stretchers is shown in Fig. 6a, after correction of dark and white fields. The image over wood - denser and thicker than canvas-is characterized of whiter range of grey levels, as the histogram of both parts reveals, in Fig. 6b. Splitting the image for processing the darker shade needs the stretching of its histogram (Fig. 6c). On the opposite, the whiter part needs stretching and shifting of the range to a lower level to get the final balanced histogram (Fig. 6c). Recomposing the total image (Fig. 6d), any detail is visible in a smooth background, with little loss of information.

All the images composing the radiography of the Previati's painting have been corrected by this way, and only after that converted to 8 bit format for the stitching project.

The enhanced readability of the radiography is shown in Fig. 7, where only the metal inserts and wooden knots are non-corrected residuals of the frame. 


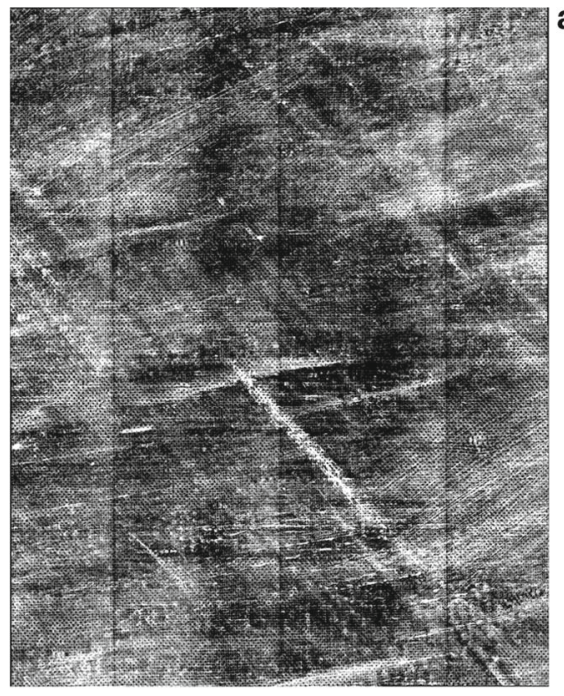

a

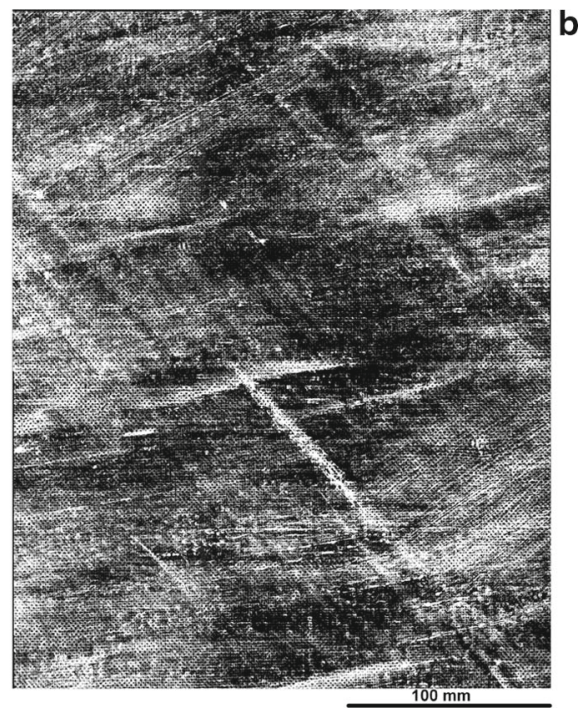

Fig. 4 Detail of the radiography of "Paolo and Francesca". a The stitching of uncorrected images with dark and white fields. It is possible to recognize the shape of single images marked on edges. b The stitching of dark-white corrected images. All the details are related to the pictorial layers and the canvas

\section{Results}

Comparing the radiography (Fig. 7) with the visible image of "Paolo e Francesca", we can recognize the canvas, a commercial one with a very thin weaving. In the pictorial layer the fast and thick brushstrokes of the artist are well evident, as in the drape accompanying the bodies in the whirl.

Many differences have been revealed in the radiography. Looking at the two protagonists (Fig. 8), in the RGB image Francesca is depicted in a different way. In the radiography she is more arched and her head is thrown back to the left. Her right arm is shifted to the right and her side is heavily warped. The figure of Francesca in the radiography is in an extreme pose compared to the RGB image. Paolo has changed a little bit his position too. In the RX image his head is turned over his left, less than in the visible image.

Looking to the other people in the composition: in the hell whirl, the damns are collocated in various poses. First, in the radiography the damn in the right central area (Fig. 9) is shifted to the left and downside and he is occupying more space than in the VIS image, where he is covering his eyes with his arm.

Second, the damn in the down-left corner (Fig. 10) in the RX image is completely laying and the observer cannot see his face, as he can in the RGB image. Again, the side of the body is more warped in the radiography than in the visible.

Finally, the radiography revealed the presence of short parallel lines, top left to right, made of a radiopaque pigment (Fig. 11). No trace is found in the visible painting and some hypothesis may be done. A coloured rain, inspired by the Canto 6 of the Divine Comedy, may be a choice.

We can conclude that the radiography, thanks to the use of more radiopaque materials, revealed the former version of the painting. It seems that the first willing of Previati was to amaze the observers with extreme poses of the bodies and the presence of the rain. Soon 


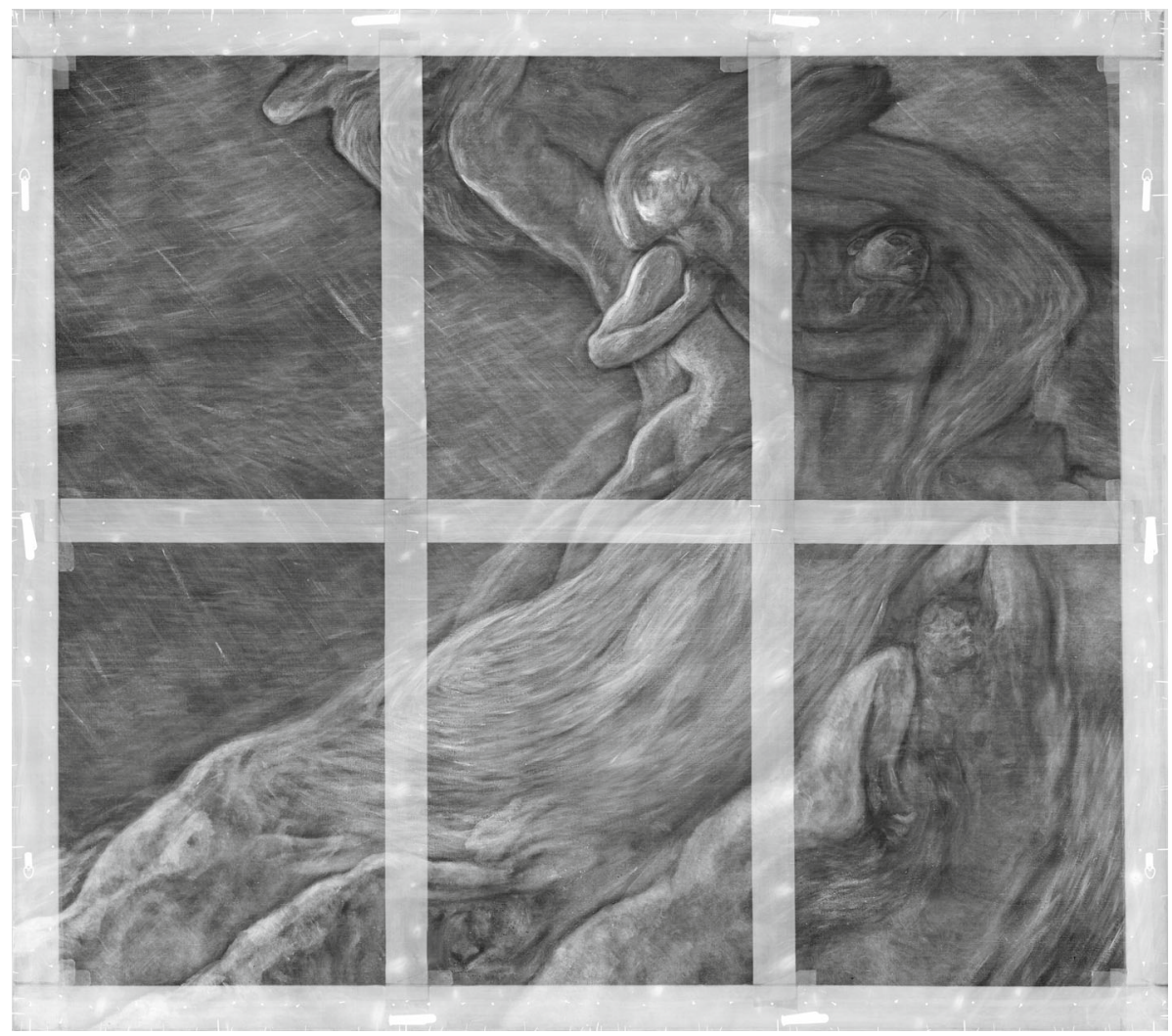

Fig. 5 X-radiography of "Paolo and Francesca", acquired with the X-ray tube set at $30 \mathrm{kV}, 6 \mathrm{~mA}$, detector acquisition time $10 \mathrm{~s}$, distance of source-detector $2 \mathrm{~m}$
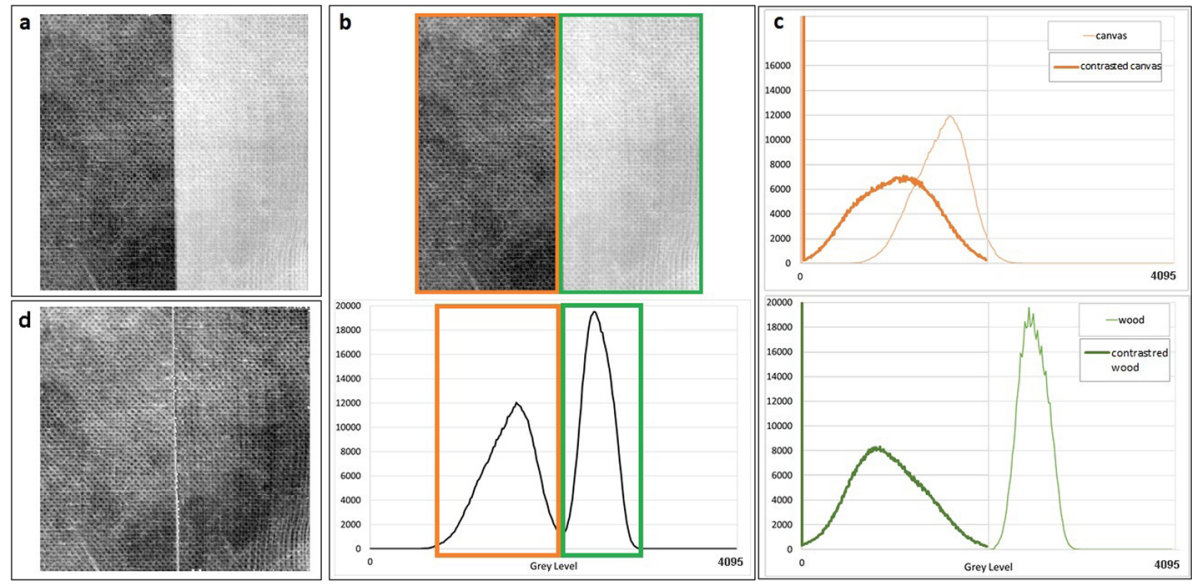

Fig. 6 Balancing histogram for wood and canvas parts in a image. a Image with canvas to the left and wood to the right. b The histogram of the image shows two peaks: one for the canvas (lower grey levels) and one for the wood (higher grey levels. c Histograms of the two parts stretched and shifted. d "Balanced histogram" final image 


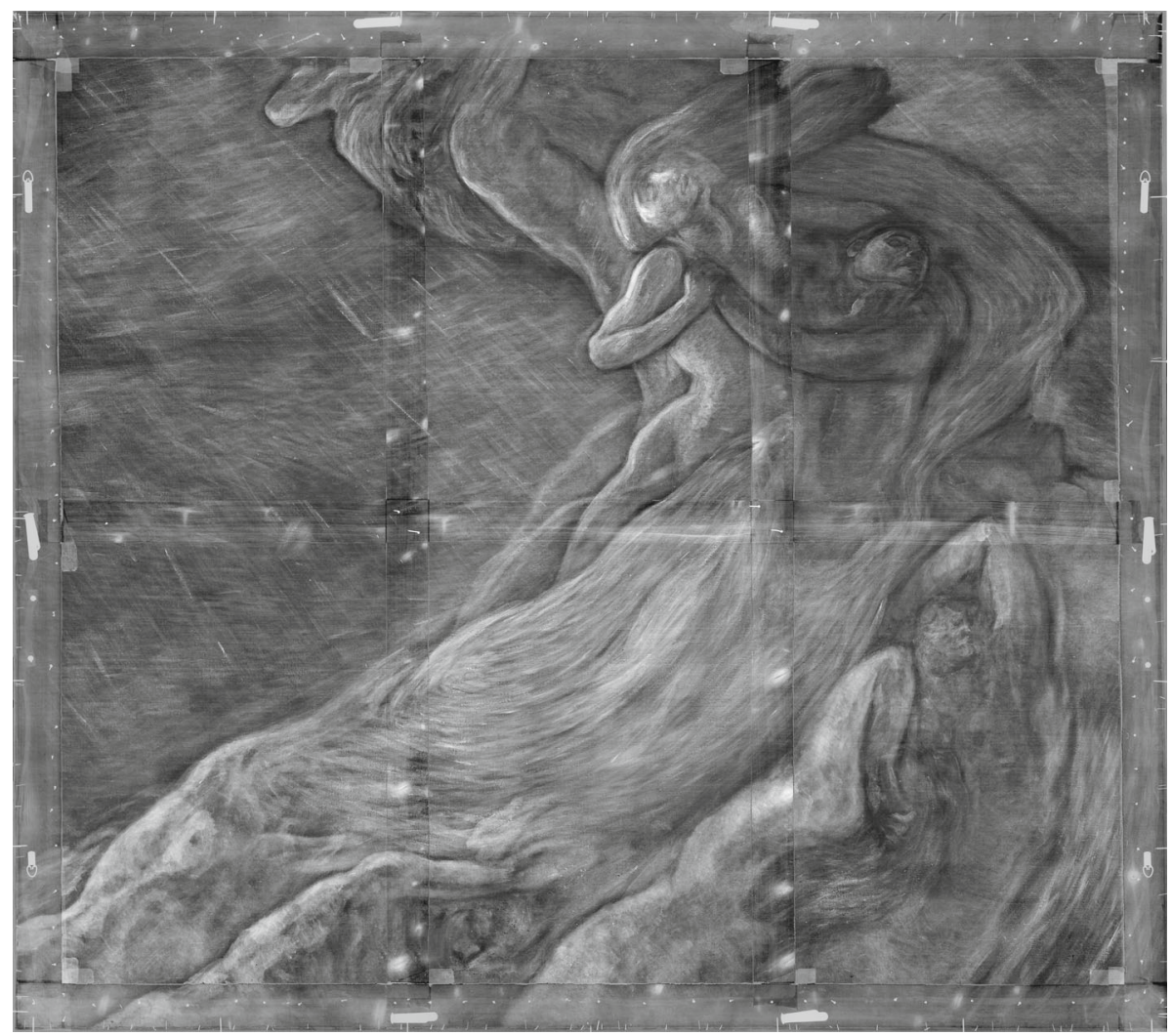

Fig. 7 "Paolo and Francesca" X-radiography with balanced histogram images. The wood stretchers are less evident, focusing on the pictorial layers contribution

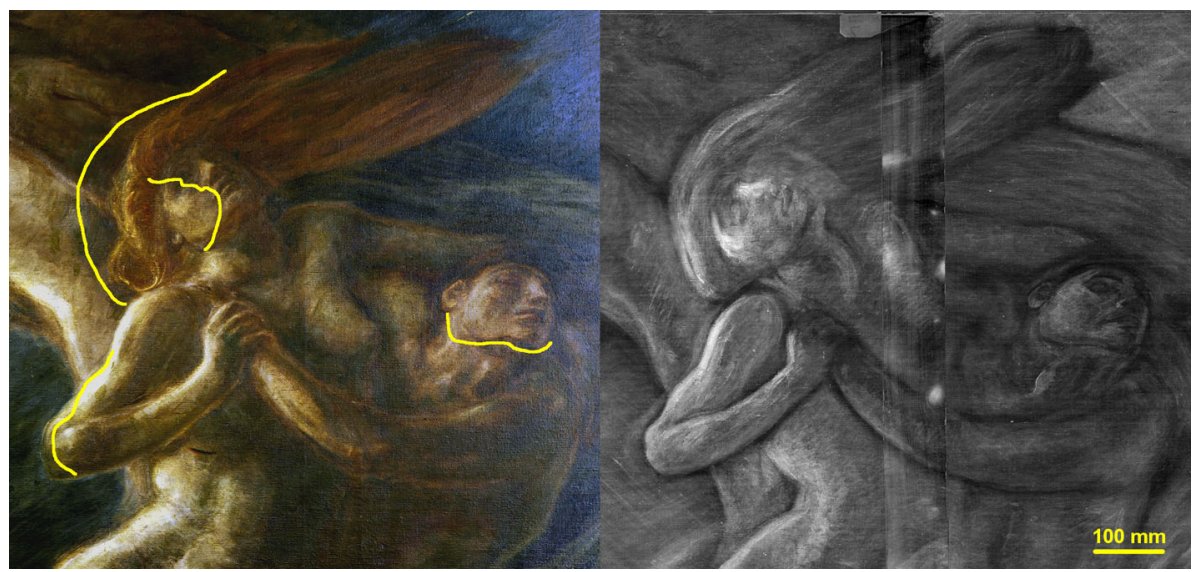

Fig. 8 Detail of Paolo and Francesca to the left. In yellow are the guides to read the differences with respect to the radiography (right) 


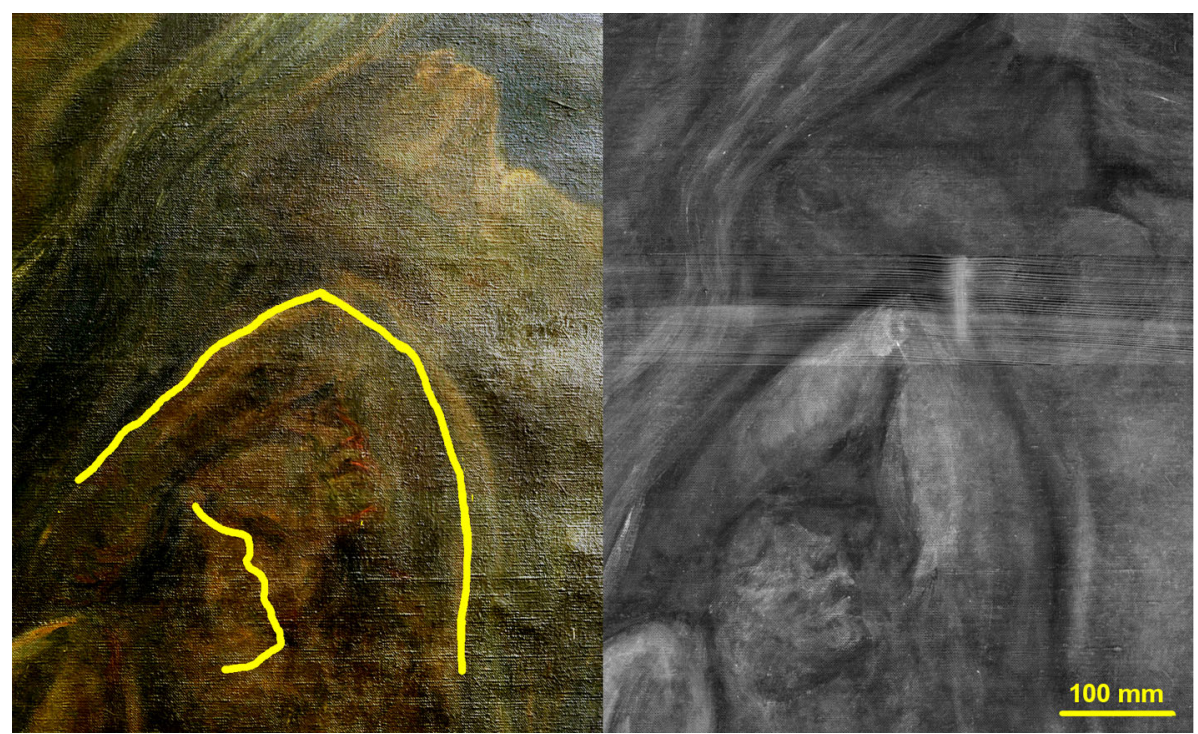

Fig. 9 To the left, detail of the damns in the right central area of the canvas. In yellow are the guides to read the differences with respect to the radiography (right)

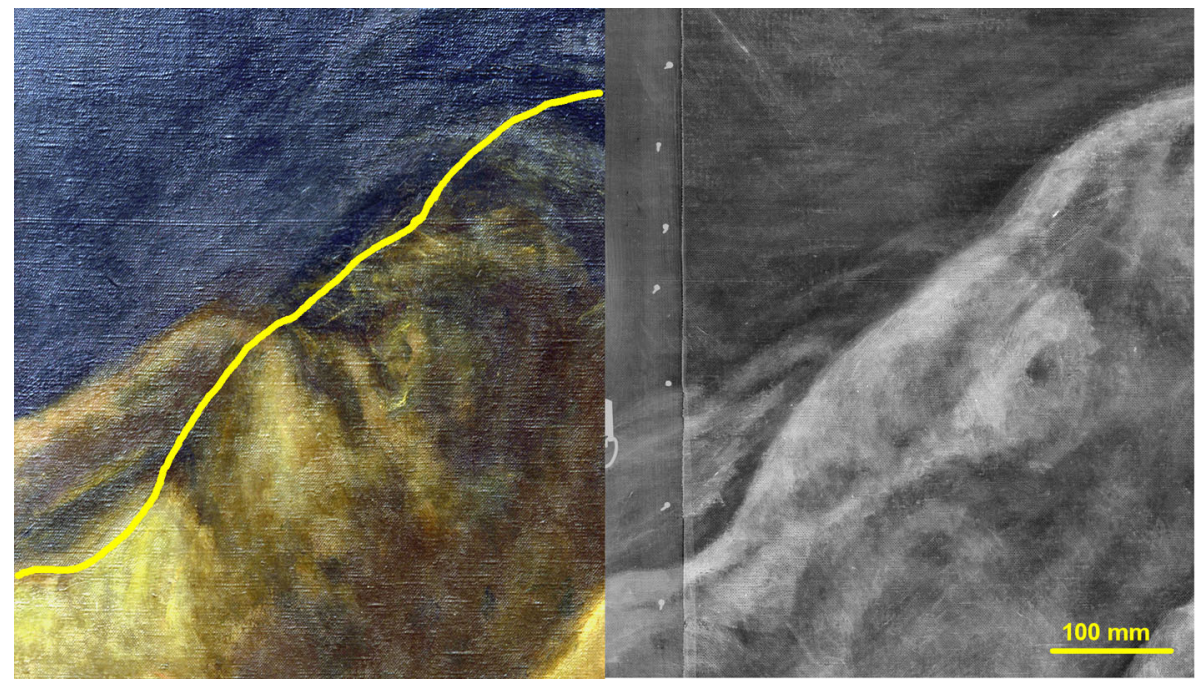

Fig. 10 To the left, detail of the damn in the down-left corner of the canvas. In yellow are the guides to read the differences with respect to the radiography (right)

after having almost concluded the representation of the scene, Previati changed his mind, creating a more equilibrate and peaceful composition. This former painting seems to be well conserved, under the visible one. 


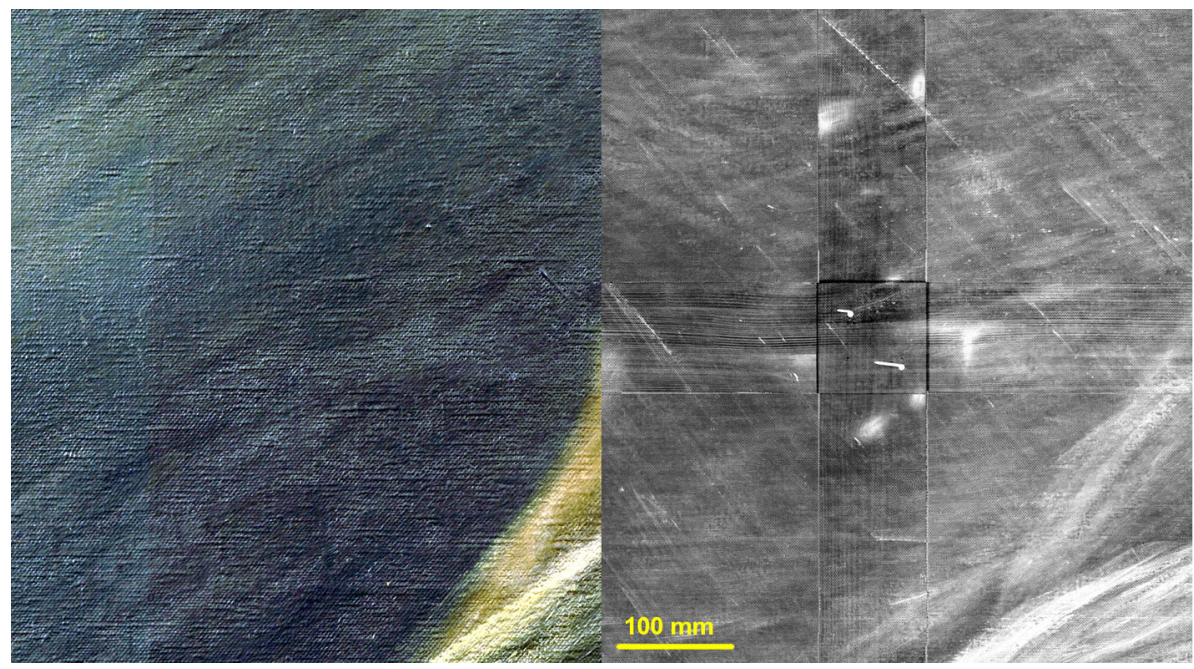

Fig. 11 To the left, detail of the sky in the left area of the painting. The radiography, to the right, shows a "rain" not visible in the final edition of the painting

\section{Conclusion}

This case study on a very large painting was the opportunity to deeply test the design, realization and work of our radiographic scanner, whose results have concerned various fields.

The resulting radiography of the Previati's work reveals the existence of a hidden painting, representing the original version of this "Paolo and Francesca" depicted by the author himself, in his wondering on the theme [25]. A small tile has been added to the evolution of this subject in the artist's poetics.

Thanks to the potentialities of digital images, the further processing carried on allowed to highlight the pictorial layers lessening the stretchers contributions. It improved a lot the readability of the radiography, resulting helpful for the presentation of the results even to non-specialized people.

We outlined the way of painting of G. Previati, based on the knowledge obtained by the very reading of the RX image and by the comparison with the visible aspect. This interpretation is not new for radiography, but we think that today this technology is ready to add something more, like the recognition of art materials, indeed one of the main trends of actual research.

Acknowledgements We gratefully acknowledge the Municipality of Ferrara for our involvement in this important project, namely the director of Galleries Maria Luisa Pacelli, the curator Chiara Vorrasi and the registrar Tiziana Giuberti. A special thanks to the staff of the Galleries, who gave effective support to our work. We likewise acknowledge Mattia Patti, from the University of Pisa, for the project coordination. On our side, we want to thank the director of INFN-Ferrara unit Raffaele Tripiccione. We add a special mention to Giulia Gollini, who got her thesis in Science and Technology for Cultural Heritage on this subject.

Funding Open Access funding provided by Università degli Studi di Ferrara.

Open Access This article is licensed under a Creative Commons Attribution 4.0 International License, which permits use, sharing, adaptation, distribution and reproduction in any medium or format, as long as you give appropriate credit to the original author(s) and the source, provide a link to the Creative Commons licence, and indicate if changes were made. The images or other third party material in this article are included in the 
article's Creative Commons licence, unless indicated otherwise in a credit line to the material. If material is not included in the article's Creative Commons licence and your intended use is not permitted by statutory regulation or exceeds the permitted use, you will need to obtain permission directly from the copyright holder. To view a copy of this licence, visit http://creativecommons.org/licenses/by/4.0/.

\section{References}

1. G. Van der Snickt, S. Legrand, I. Slama, E. Van Zuien, G. Gruber, K. Van der Stighelen, L. Klaassen, E. Oberthaler, K. Janssens, Microchem. J. 138, 238-245 (2018)

2. G. Barone, P. Mazzoleni, A. Cecchini, A. Russo, Dyes Pigments 150, 390-403 (2018)

3. V. Venuti, B. Fazzari, V. Crupi, D. Majolino, G. Paladini, G. Morabito, G. Certo, S. Lamberto, L. Giacobbe, Spectrochim. Acta Part A 228, 117822 (2020)

4. E.H. Zidan, S. Mosca, S. Bellei, T. Frizzi, M. Gironda, I. El-Rifai, H. Mahgoub, S. Sadik, M. Gamal Rashed, I. Osticioli, S. Siano, G. Valentini, A. Elnaggar, A. Nevin, D. Comelli, Measurement 118, 379_ 386 (2018)

5. F. Albertin, M. Bettuzzi, R. Brancaccio, M.B. Toth, M. Baldan, M.P. Morigi, F. Casali, Microchem. J. 158, $105203(2020)$

6. M. Alfeld, L. de Viguerie, Spectrochim. Acta Part B 136, 81-105 (2017)

7. G. Vittiglio, S. Bichlmeier, P. Klinger, J. Heckel, W. Fuzhong, L. Vincze, K. Janssens, P. Engstrom, A. Rindby, K. Dietrich, D. Jembrih-Simburger, M. Schreiner, D. Denis, A. Lakdar, A. Lamotte, Nucl. Instrum. Methods Phys. Res. B 213, 693-698 (2004)

8. K. Laclavetine, F.J. Ager, J. Arquillo, M. Ángel Respaldiza, S. Scrivano, Microchem. J. 125, 62-68 (2016)

9. F.J. Ager, M.A. Respaldiza, S. Scrivano, I. Ortega-Feliu, A. Kriznar, B. Gómez-Tubío, Radiat. Phys. Chem. 167, 108324 (2020)

10. P.H.O.V. Campos, C.R. Appoloni, M.A. Rizzutto, A.R. Leite, R.F. Assis, H.C. Santos, T.F. Silva, C.L. Rodrigues, M.H. Tabacniks, N. Added, Appl. Radiat. Isot. 152, 78-85 (2019)

11. G. Capobianco, C. Pelosi, G. Agresti, G. Bonifazi, U. Santamaria, S. Serranti, J. Cult. Herit. 29, 19-29 (2018)

12. F.P. Romano, L. Pappalardo, G. Calvi, E. Costa, C. Marchetta, G. Pappalardo, F. Rizzo, S. Russo, Microchem. J. 101, 95-98 (2012)

13. E. Catelli, G. Sciutto, S. Prati, M. Valente Chavez Lozano, L. Gatti, F. Lugli, S. Silvestrini, S. Benazzi, E. Genorini, R. Mazzeo, Talanta 218, 121112 (2020)

14. I. Arrizabalaga, O. Gómez-Laserna, J. Aramendia, G. Arana, J.M. Madariaga, Spectrochim. Acta Part A 129, 259-267 (2014)

15. P. Siozos, A. Philippidis, D. Anglos, Spectrochim. Acta Part B 137, 93-100 (2017)

16. N. de Manincor, G. Marchioro, E. Fiorin, M. Raffaelli, O. Salvadori, C. Daffara, Microchem. J. 153, 104469 (2020)

17. F.C. Agnoletto, L. de Ferri, D. Bersani, G. Pojana, Spectrochim. Acta Part A 229, 117954 (2020)

18. F. Albertin, M. Bettuzzi, R. Brancaccio, M.P. Morigi, F. Casali, Heritage 2, 2028-2038 (2019)

19. A. Impallaria, F. Evangelisti, F. Petrucci, F. Tisato, L. Castelli, F. Taccetti, Appl. Phys. A 122, 1043 (2016)

20. A. Lo Giudice, J. Corsi, G. Cotto, G. Mila, A. Re, C. Ricci, R. Sacchi, L. Visca, L. Zamprotta, N. Pastrone, F. Albertin, R. Brancaccio, G. Dughera, P. Mereu, A. Staiano, M. Nervo, P. Buscaglia, A. Giovagnoli, N. Grassi, in 2017 Proceedings of the IEEE International Instrumentation and Measurement Technology Conference, I2MTC 2017

21. A. Re, F. Albertin, C. Bortolin, R. Brancaccio, P. Buscaglia, J. Corsi, G. Cotto, G. Dughera, E. Durisi, W. Ferrarese, M. Gambaccini, A. Giovagnoli, N. Grassi, A. LoGiudice, P. Mereu, G. Mila, M. Nervo, N. Pastrone, F. Petrucci, F. Prino, L. Ramello, M. Ravera, C. Ricci, A. Romero, R. Sacchi, A. Staiano, L. Visca, L. Zamprotta, IOP Conf. Ser.: Mater. Sci. Eng. 37, 012007 (2012)

22. F. Albertin, L. Boselli, S. Chiozzi, E. Peccenini, V. Pellicori, F. Petrucci, G. Poldi, F. Tisato, Progetto Restauro 65, 40-48 (2013)

23. E. Peccenini, F. Albertin, M. Bettuzzi, R. Brancaccio, F. Casali, M.P. Morigi, F. Petrucci, J. Phys.: Conf. Ser. 566, 012022 (2014)

24. A. Impallaria, F. Petrucci, S. Bruno, Heritage 2, 2183-2192 (2019)

25. M. Patti, R. Fontana, M. Raffaelli, G. Gollini, A. Impallaria, F. Petrucci, F. Tisato, Stati d'animo. Arte e psiche tra Previati e Boccioni (Fondazione Ferrara Arte, Ferrara 2018), p. 182-187

26. M. Alfeld, J.A.C. Broekaert, Spectrochim. Acta Part B 88, 211-230 (2013)

27. J. Padfield, D. Saunders, J. Cupitt, R. Atkinson, National Gallery Technical Bullettin 23, 62-75 (2002) 